\title{
Study on the Characteristics and Production Techniques of the Clay Seated Vairocana Buddha Triad of Seonunsa Temple, Gochang(2) - Analysis of Gold Leaf Layers and Internal Structure of the Clay Buddha Statues
}

\author{
Hwa Soo Lee', Seol Hui $\mathrm{Kim}^{2}$, Won Woo Kim³ , Yeong Gyeong $\mathrm{Yu}^{4}$, Kyeong Soon $\mathrm{Han}^{5^{*}}$ \\ ${ }^{I}$ Department of Formative Arts, Konkuk University, Chungju 27478, Korea \\ ${ }^{2}$ Cultural Heritage Conservation Science Center, National Research Institute of Cultural Heritage, Daejeon 34122, Korea \\ ${ }^{3}$ Georim Cultural Properties, Jeonju 55024, Korea \\ ${ }^{4}$ Department of Fine Arts, Graduate School of Konkuk University, Chungiu 27478, Korea \\ ${ }^{5}$ Institute of Conservation of Paintings, Konkuk University, Chungiu 27478, Korea
}

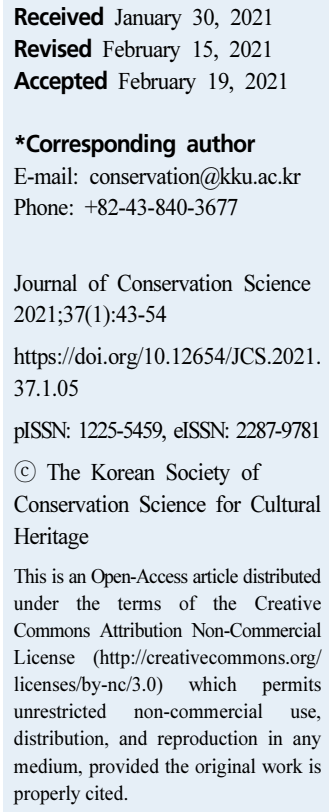

\begin{abstract}
In this study, a scientific analysis of the gold leaf layers and internal structure of the Clay Seated Vairocana Buddha Triad in Seonunsa Temple, Gochang (Treasure No. 1752) was conducted. The surface of the Buddha statues is a gold foil, and the gold leaf layer consists of four layers. The gold leaf layer first composed on the molding clay was produced in the order of lacquer-fabrics-lacquer-gold foil. Subsequently, it was confirmed that the work was performed three times in the same way. The composition of the Buddha statues was divided into the head, body or upper body, lower body, and pedestal. The body was made in a cylindrical form by connecting vertically oriented wooden materials, and the head and lower body were also connected to the body in an empty form. Thus, the head, body, and lower body are grafted structures that are connected to a single Bokjang-gong. It was confirmed that the Clay Seated Vairocana Buddha Triad in Seonunsa Temple was made using wood materials for the basic form, after which the detailed form was created with molding clay, and the surface was finished with a process of layering gold foil and substances presumed to be lacquer.
\end{abstract}

Key Words Clay Buddha statues, Gold leaf layers, Internal structure, Manufacturing technique, Conservation

\section{INTRODUCTION}

Clay Buddha statues, which have material characteristics composed of soil and wood, require routine investigations of their conservation condition. In addition, studies on material properties and manufacturing techniques can be used as important information for the treatment or continuous conservation management of damaged Buddha statues.

The Clay Seated Vairocana Buddha Triad of Seonunsa Temple, located on the Buddhist altar inside Daeungjeon Hall of Seonunsa Temple in Gochang, is a Buddhist sculpture representing small statues of Buddha with an outstanding Buddha image, and it has been designated and preserved as Treasure No. 1752. According to the results from a conservation diagnosis and investigation conducted in 2017, it was reported that the clay Buddha statues had cracks on the surface and damage to the gold leaf layer (Georim Culture Heritage and Gochang-gun, 2018).

In 2020, analyses were conducted to identify the main constituent materials of the clay Buddha statues. The analyses 
focused mainly on the following items: the molding clay soil components and species of mixed fibers, the basic status of the gold leaf layer, the wood species of the basic skeleton of the Buddha statue, and the material of Nabal (Lee et al., 2020). Following the first study, the present study is conducted to obtain more details regarding the manufacturing technique of the Clay Seated Vairocana Buddha Triad of Seonunsa Temple. The research is based on an accurate analysis of the gold leaf layer and internal structure of the three clay Buddha statues. In addition, through the research results of series No. 1 and No. 2, this study aims to provide a comprehensive investigation of the material characteristics and manufacturing techniques of the Clay Seated Vairocana Buddha Triad of Seonunsa Temple. The research results can be used as a reference for the manufacturing technology of clay Buddha statues in Korea and can also serve as useful data for the conservation and management of Buddha statues in the future.

\section{METHOD}

\subsection{Analysis target and content}

Analysis of gold leaf layers was conducted on five samples collected from the three Buddha statues during the treatment process of the Clay Seated Vairocana Buddha Triad at Daeungjeon, Seonunsa Temple in 2019 (Table 1). The internal structures of the Buddha statues were analyzed based on the results of radiographic irradiation conducted during the diagnosis and investigation of the conservation condition of the clay Buddha statues in 2017 (Figure 1).

Table 1. List of analysis of gold leaf layers for the Clay Buddha statues

\begin{tabular}{|c|c|c|c|c|c|}
\hline Sample name & Category & Location & Analysis & equipment & Classification \\
\hline GL-1 & Medicine Buddha & Left knee of the Buddha statue & \multirow{5}{*}{$\begin{array}{l}\text { Digital } \\
\text { microscope }\end{array}$} & \multirow{5}{*}{ SEM-EDS } & \multirow{5}{*}{$\begin{array}{l}\text { Gold leaf } \\
\text { layer }\end{array}$} \\
\hline GL-2 & \multirow{3}{*}{ Vairocana Buddha } & Left waist of the Buddha statue & & & \\
\hline GL-3 & & Right bottom board of the Buddha statue & & & \\
\hline GL-4 & & Backside of the Buddha statue & & & \\
\hline GL-5 & Amitabha Buddha & Backside of the Buddha statue & & & \\
\hline
\end{tabular}
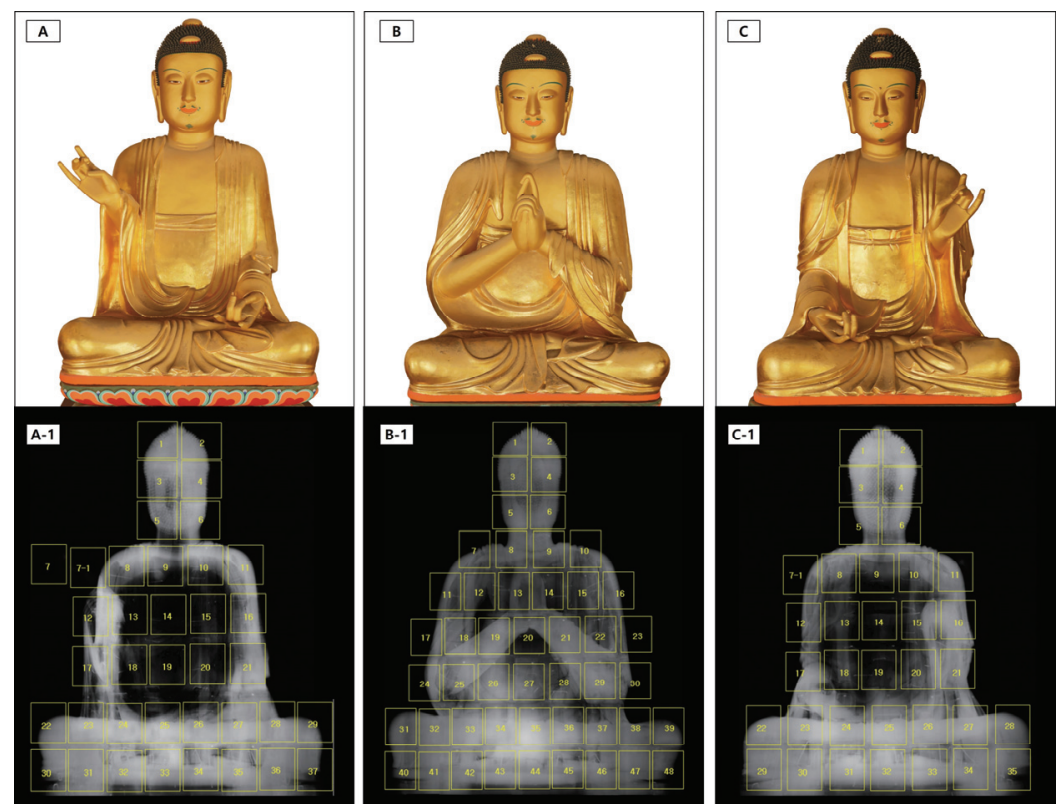

Figure 1. Current status of radiographic targets and film layout. 


\subsection{Analysis of the gold leaf layer}

\subsubsection{Microscopy}

Cold mounting of the samples was performed with epoxy resin, and the surface was polished in the order of $\# 1000$, \#2400, \#4000, and \#1 $\mu \mathrm{m}$. A 3D microscope (Digital Microscope; DVM6, Leica, DEU) was used to identify the sectional characteristics and thickness of each layer for the processed samples.

\subsubsection{SEM-EDS}

After the completion of microscopy, microstructure observations and chemical composition analyses were conducted on the samples using a scanning electron microscope with an energy-dispersive florescence X-ray analyzer (SEM-EDS; EM30AX, Coxem, KOR). The results of the material characteristics analyses and visual surveys of the gold leaf layer were compared.

\subsection{Radiographic analysis}

Radiography was performed on the front of the three clay Buddha statues. The radiographic conditions were a $\gamma$-ray source with a source intensity of $20 \mathrm{Ci}$, FUJI \#100 film, a distance of $4.2 \mathrm{~m}$, and an exposure time of $2 \mathrm{~h} 30 \mathrm{~min}$. Through the images captured by the radiographic film, features that cannot be observed with the naked eye could be identified in detail, such as the internal condition of the Buddha statue, the joinery techniques, internal damage (such as to the wood and molding clay), and the existence of repairs.

\section{RESULTS}

\subsection{Gold leaf layer}

\subsubsection{Microscopy}

Samples GL-1, GL-2, GL-3, and GL-5 have a ground layer at the lowermost part of the gold leaf layer, and samples GL-1, GL-2, and GL-5 have a lacquer layer that includes fabric. On top of that, there is a first gold leaf layer, which is composed of presumed lacquer material $\rightarrow$ gold leaf $\rightarrow$ presumed lacquer material $\rightarrow$ gold leaf. Next, there is a white filling layer, followed by the second gold leaf layer. The second gold leaf layer is also composed of presumed lacquer material $\rightarrow$ gold leaf $\rightarrow$ presumed lacquer material $\rightarrow$ gold leaf, similar to the first gold leaf layer. White treatment materials are present in the gold leaf layer of sample GL-4, and a filling layer containing fabric is present above the layer. Lastly, there is a gold leaf layer in the order of lacquer $\rightarrow$ gold leaf $\rightarrow$ lacquer $\rightarrow$ gold leaf (Figure 2).

The lacquer layers included in the gold leaf layer have thicknesses ranging from $8 \mu \mathrm{m}$ to $120 \mu \mathrm{m}$ depending on the location, whereas the gold leaf thickness ranges from $2 \mu \mathrm{m}$
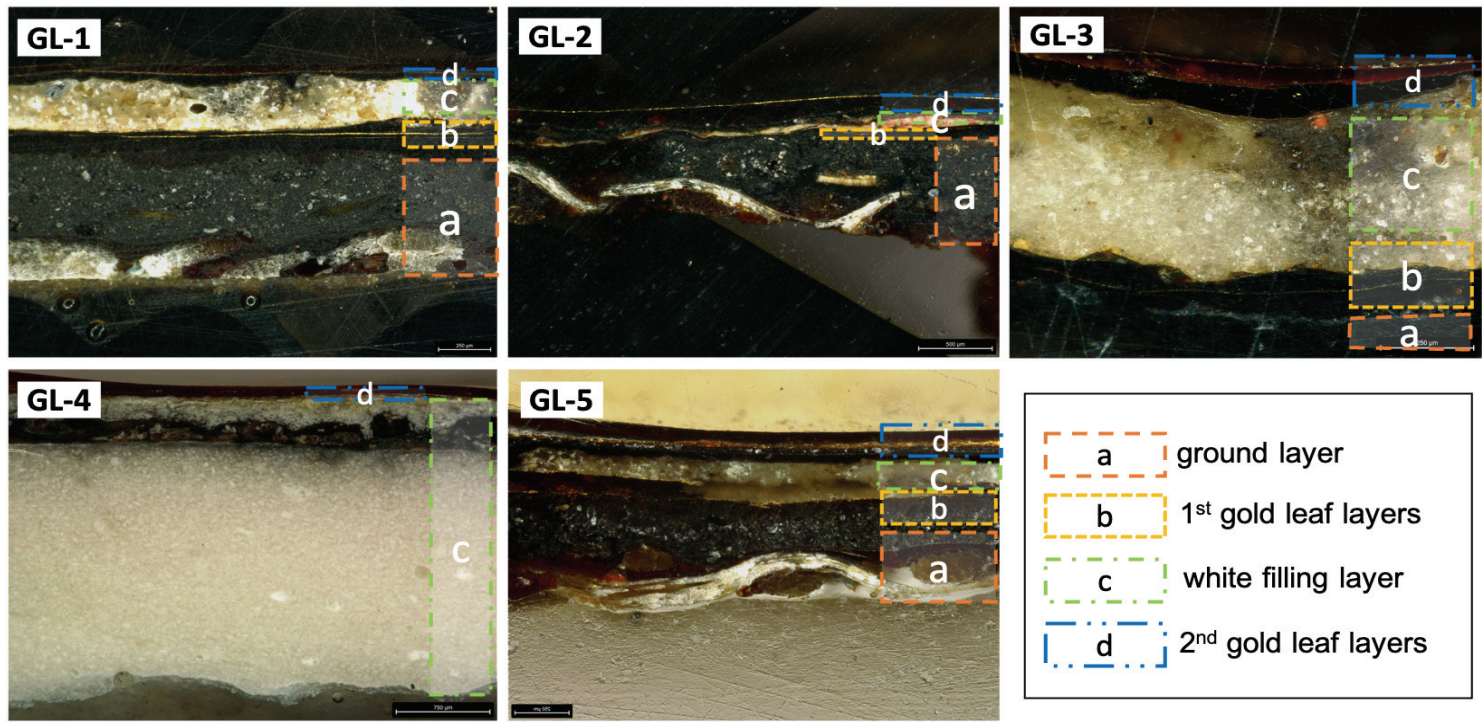

Figure 2. Classification of layers((a): ground layer, (b): $1^{\text {st }}$ gold leaf layers, (c): white filling layer, (d): $2^{\text {nd }}$ gold leaf layers). 
to $5 \mu \mathrm{m}$. The thickness of the filling layer exhibits significant differences depending on the sample, ranging from $18 \mu \mathrm{m}$ to $400 \mu \mathrm{m}$.

\subsubsection{SEM-EDS}

The microstructures of the five samples were observed, and elemental mapping was conducted at the same time (Figure 3, Table 2). In sample GL-1, calcium (Ca) and silicon (Si) were observed in the filling layer, and gold $(\mathrm{Au})$ was identified in the gold leaf layer. In the second gold layer of the first gold leaf layer, copper $(\mathrm{Cu})$ and chlorine $(\mathrm{Cl})$ were identified. In sample GL-2, magnesium $(\mathrm{Mg})$, calcium $(\mathrm{Ca})$,
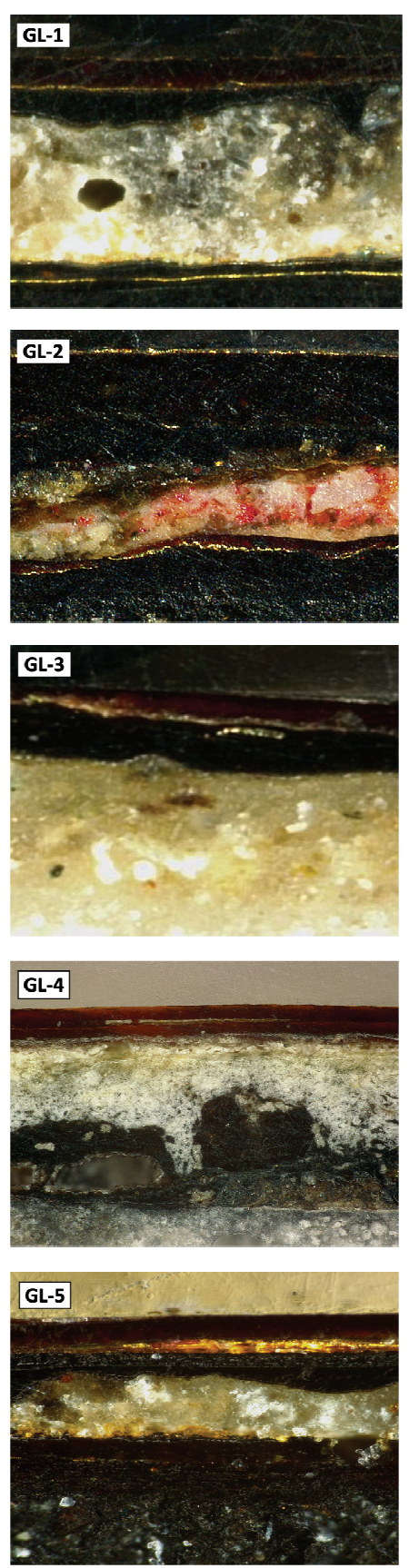
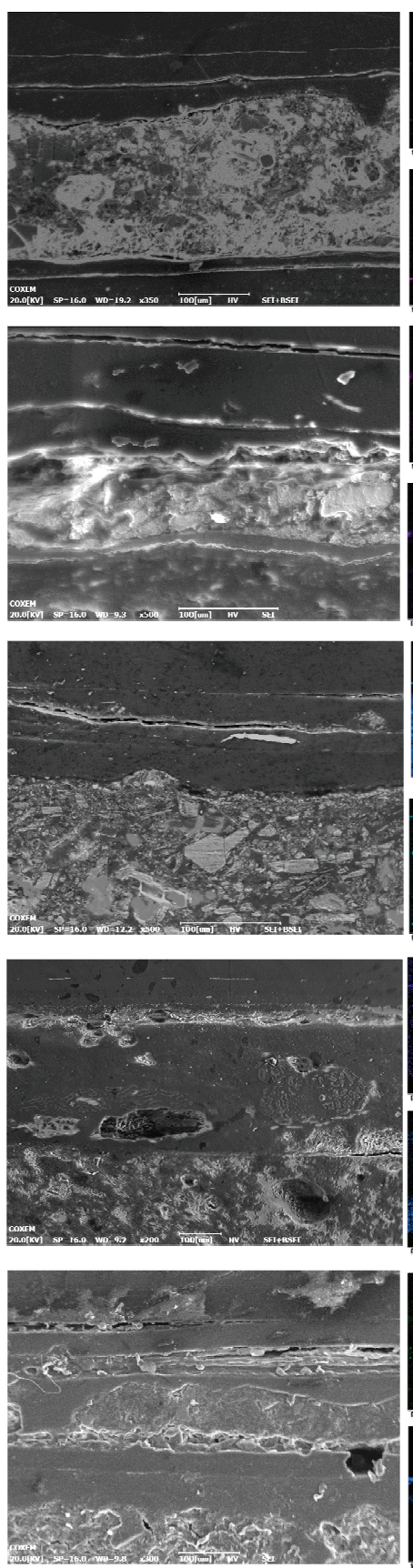
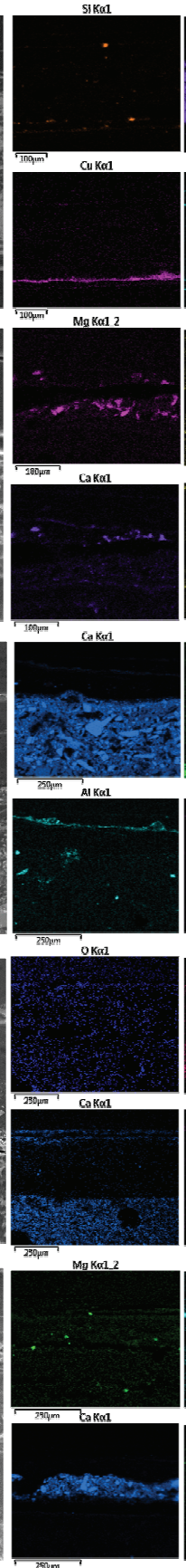

$25 \% m$
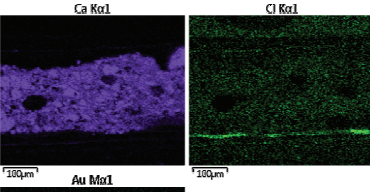

ingoum
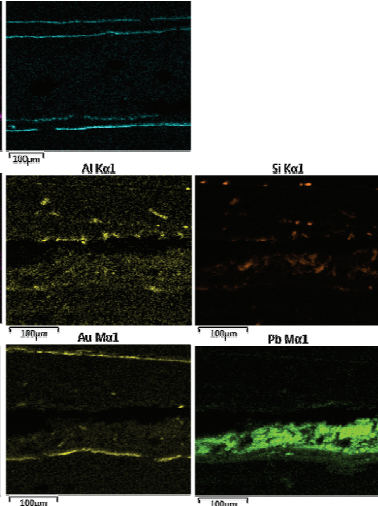

100, Mata

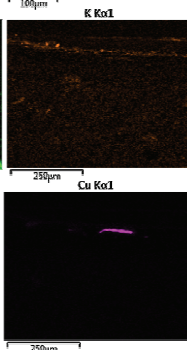

$355 \mathrm{pm} 5 \mathrm{~s} \mathrm{kal}$
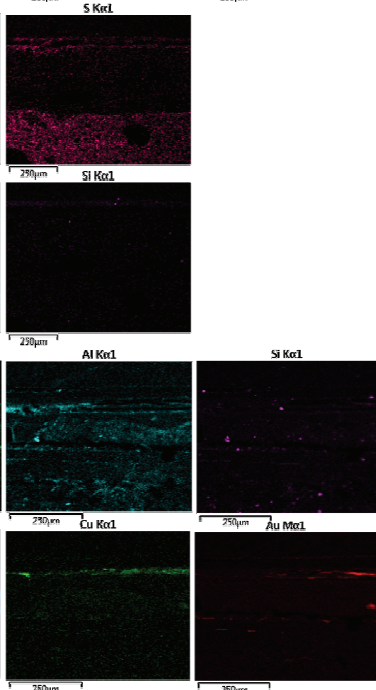

Figure 3. SEM-EDS mapping analysis results. 
Study on the Characteristics and Production Techniques of the Clay Seated Vairocana Buddha Triad of Seonunsa Temple, Gochang(2) / Hwa Soo Lee et al. I 47 Study on the Characteristics and Production Techniqu of the Clay Seated Vairocana Buddha Triad of Seonuna Temple, Gochangl2)/Hwa Soo Lee et al. 47 .

Table 2. SEM-EDS chemical components analysis results

\begin{tabular}{|c|c|c|c|}
\hline Sample name & $\begin{array}{l}\text { Detected elements } \\
\text { (mapping method) }\end{array}$ & Point analysis number & $\begin{array}{l}\text { Detected elements } \\
\text { (point method) }\end{array}$ \\
\hline \multirow{3}{*}{ GL-1 } & \multirow{3}{*}{$\mathrm{Si}, \mathrm{Ca}, \mathrm{Cl}, \mathrm{Cu}, \mathrm{Au}$} & GL-1a & $\mathrm{Au}$ \\
\hline & & GL-1b & $\mathrm{Ca}$ \\
\hline & & GL-1c & $\mathrm{Ca}, \mathrm{Cu}, \mathrm{Cl}$ \\
\hline \multirow{2}{*}{ GL-2 } & \multirow{2}{*}{$\mathrm{Mg}, \mathrm{Al}, \mathrm{Si}, \mathrm{Ca}, \mathrm{Au}, \mathrm{Pb}$} & GL-2a & $\mathrm{Au}$ \\
\hline & & GL-2b & $\mathrm{Pb}$ \\
\hline \multirow{2}{*}{ GL-3 } & \multirow{2}{*}{$\mathrm{Ca}, \mathrm{Mg}, \mathrm{K}, \mathrm{Al}, \mathrm{Si}, \mathrm{Cu}$} & GL-3a & $\mathrm{Ca}, \mathrm{Mg}$ \\
\hline & & GL-3b & $\mathrm{Au}$ \\
\hline \multirow{2}{*}{ GL-4 } & \multirow{2}{*}{$\mathrm{S}, \mathrm{Ca}, \mathrm{Si}$} & GL-4a & $\mathrm{Ca}, \mathrm{S}$ \\
\hline & & GL-4b & $\mathrm{Ca}, \mathrm{S}$ \\
\hline \multirow{2}{*}{ GL-5 } & \multirow{2}{*}{$\mathrm{Mg}, \mathrm{Al}, \mathrm{Si}, \mathrm{Ca}, \mathrm{Cu}, \mathrm{Au}$} & GL-5a & $\mathrm{Au}$ \\
\hline & & GL-5b & $\mathrm{Ca}$ \\
\hline
\end{tabular}
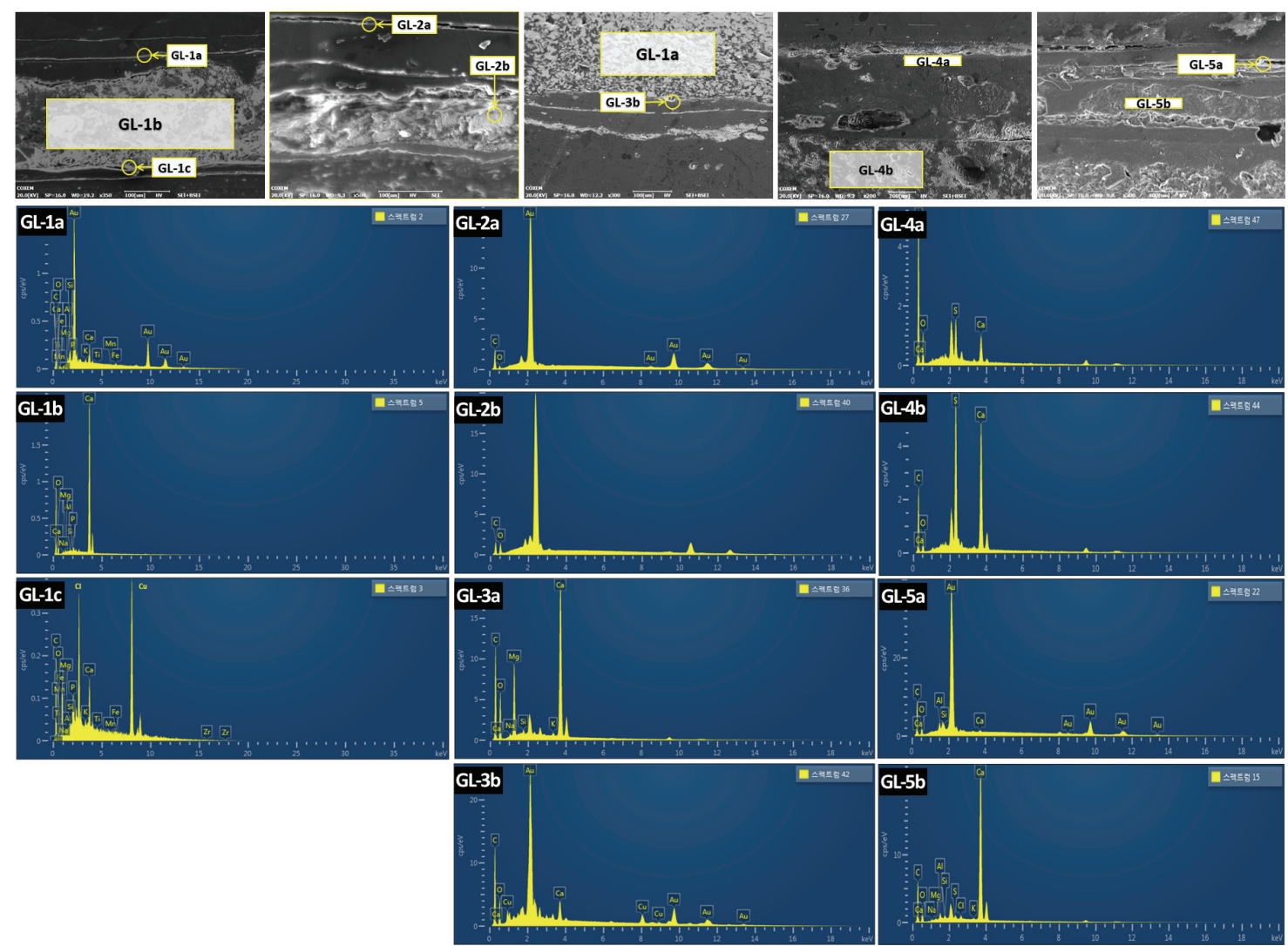

Figure 4. SEM-EDS point analysis results.

aluminum $(\mathrm{Al})$, silicon $(\mathrm{Si})$, and lead $(\mathrm{Pb})$ were identified in the filling layer, and gold $(\mathrm{Au})$ was identified in the gold leaf layer. In sample GL-3, calcium (Ca), magnesium (Mg), aluminum $(\mathrm{Al})$, silicon $(\mathrm{Si})$, and copper $(\mathrm{Cu})$ were observed in the filling layer, and some parts of the lacquer layer in the second gold leaf layer also showed the presence of copper $(\mathrm{Cu})$. In sample GL-4, sulfur (S), calcium (Ca), and aluminum ( $\mathrm{Al}$ ) were identified in the filling layer; in sample 
GL-5, calcium $(\mathrm{Ca})$, magnesium $(\mathrm{Mg})$, aluminum $(\mathrm{Al})$, and silicon $(\mathrm{Si})$ were observed in the filling layer. In the first gold layer of the second gold leaf layer, copper $(\mathrm{Cu})$ and gold $(\mathrm{Au})$ were observed.

EDS point analysis was performed to confirm the chemical composition of each sample (Table 2, Figure 4). Sample GL-1 showed gold (Au) in the gold leaf layer (GL-1), whereas in the filling layer (GL-1b), calcium (Ca) was identified as the main component. On the upper part of the second gold layer of the first gold leaf layer, where copper $(\mathrm{Cu})$ was identified in the elemental mapping, copper $(\mathrm{Cu})$ and chlorine $(\mathrm{Cl})$ were identified along with calcium $(\mathrm{Ca})$. In sample GL-2, gold $(\mathrm{Au})$ was observed in the uppermost gold leaf layer (GL-2a), and a clear peak of lead $(\mathrm{Pb})$ was observed in the filling layer (GL-2b). In sample GL-3, calcium $(\mathrm{Ca})$ and magnesium $(\mathrm{Mg})$ were found in the filling layer (GL-3a), and gold ( $\mathrm{Au}$ ) was observed in the second gold layer of the first gold leaf layer. In the filling layer (GL-4a) and treatment material layer (GL-4b) under the gold leaf layer of sample GL-4, calcium (Ca) and sulfur (S) were observed. Gold $(\mathrm{Au})$ was observed in the first gold layer (GL-5a) of the second gold leaf layer in sample GL-5, and calcium $(\mathrm{Ca})$ was observed in the filling layer (GL-5b).

\subsection{Radiographic}

\subsubsection{Vairocana Buddha}

(1) Head

The head of the Vairocana Buddha is empty inside the Bokjang-gong (enclosed space for fabrics in the Buddha) (Figure 5 (A-1)), and the ears seem to have been fixed on the left and right sides of the head using two straight nails (Figure $5(\mathrm{~A}-2)$ ). The state of the material used in the head part was not clearly identified as the radiographic image was frontal, but the joint parts were identified as connections between the left and right sides of the head and the wood material in the center (Figure 5 (A-3)). Tiny cracks were observed inside and outside the head image, and thus it is believed that the wood material surface was finished with soil (Figure 5 (B-1)). The Bokjang-gong of the head is a structure connected through the neck to the body, and based on the condition of the wood grain shape, it appears that the material parts were connected from the head to neck (Figure $5(\mathrm{C}-1)$ ). A large crack was identified in the lower neck area and was considered to be a crack in the molding clay layer located on the surface of the wood, rather than in the wood material (Figure 5 (C-2))

(2) Body

From the body to both arms, the thick dark lines that appear vertically seem to be attributable to the joints of the wood material parts (wooden boards) used to form the body, and the wood grain shape was also found to be consistent along most of the joints (Figure 6 (A-1, A-2)). The joint wood grain shapes of these wood material parts are thought to be connected from the body to the lower body. A clamp shape is positioned at regular intervals on the vertical wood material parts (Figure 6 (A-3)). Accordingly, the body of the Vairocana Buddha was constructed by grafting vertical wood materials, and the inside was made for the Bokjang-gong. The condition of the wood grain shape that runs down from the neck indicates that the head and body are connected (Figure 6 (B-1)). From the inside of the body to the shoulder
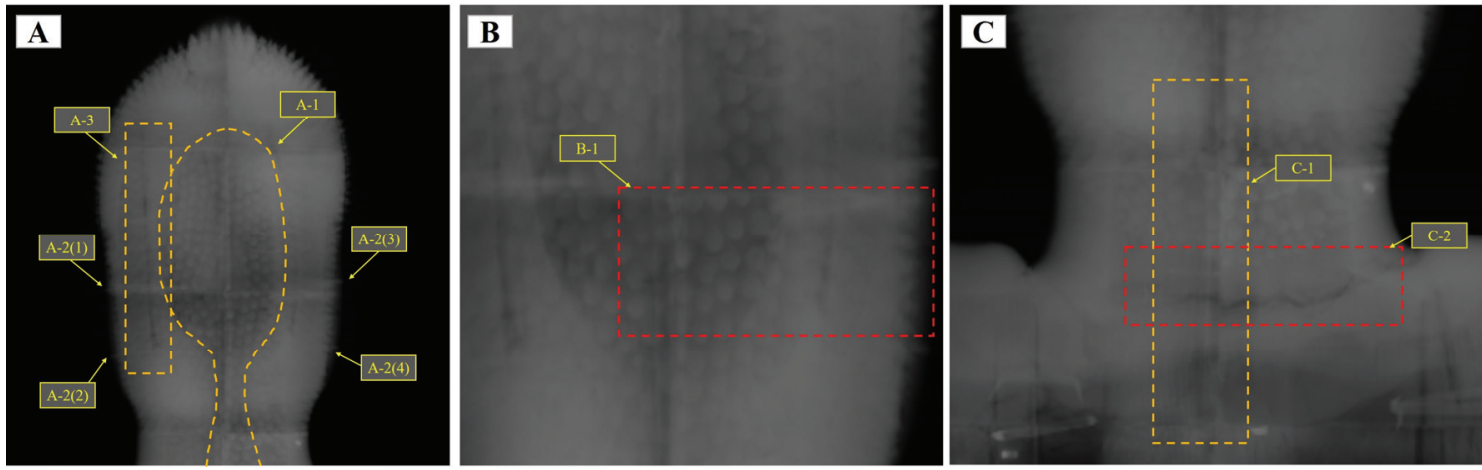

Figure 5. Radiography results of the head (Vairocana Buddha). 
and the outside of the arms, overall cracks in the molding clay layer were found, and most of the Buddha's forms appear to have been formed and then finished with soil on the wood surface (Figure 6 (B-2, C-1)). A number of large and small cracks found in various parts of the body appear to have been caused by the molding clay layer finishing on the surface of the wood, and large horizontal cracks found in the chest area where the hand sign is located are also considered to be cracks in the molding clay layer caused by the formation of the clothes using soil (Figure 6 (A-4)). Considering that traces of irregular nails are clearly visible on the left shoulder in contrast to the right shoulder, it is believed that they represent a repair of structural defects in the left shoulder production process or past repairs that are different from the production process (Figure 6 (A-5)). In addition, a number of nails appear to have been used to repair the structural stability in the area where the arm is bent.
(3) Lower body

In the case of the lower body, the transmittance was very low, which limited our understanding of the internal status. However, it was identified that a number of iron nails and clamp shapes were used to connect the base plate and the lower body (Figure 7 (A-1, A-2, B-2)). Furthermore, the cracks in the molding clay layer outside the lower body, along with the traces of wood grain shapes in various parts of the lower body, indicate that the lower body, like the body, was formed and finished with soil (Figure 7 (C-2)).

Although it is difficult to identify clearly owing to its low transmittance, in general overall form, the lower body is also empty inside for the Bokjang-gong (Figure 7 (B-1)). Moreover, as traces of the wood grain shape of the body and the connection to the lower body are visible, the back of the Buddha statue is considered to have a single wood material structure connected from the body to the lower body (Figure 7 (C-1)).
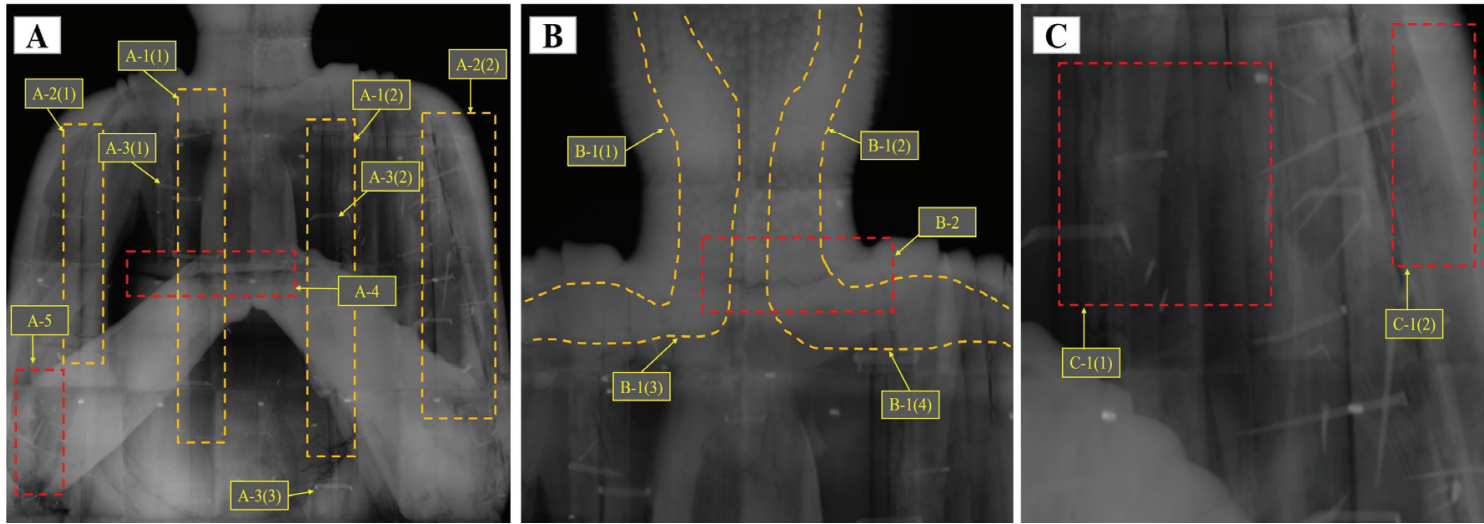

Figure 6. Radiography results of the body (Vairocana Buddha).
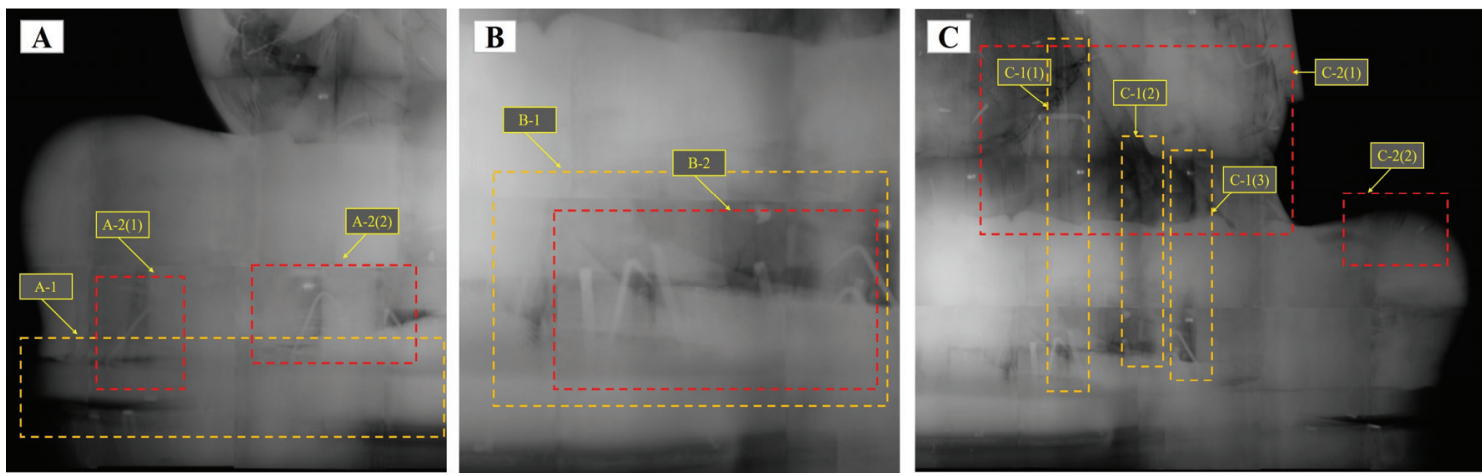

Figure 7. Radiography results of the lower body (Vairocana Buddha). 


\subsubsection{Amitabha Buddha}

\section{(1) Head}

The radiographic analysis of the head of the Amitabha Buddha suggests that the wood material part was connected to create the head, and the interior was designed for use as a Bokjang-gong (Figure 8 (A-1)). Two straight nails were used to fix the ears on each side of the head (Figure 8 (B-1)). Large and small cracks were identified inside the head, most of which are thought to be cracks in the molding clay layer on the wood surface (Figure 8 (B-4)). It is believed that the wood grain shapes identified in the head are connected to the neck and body, indicating that the head and body are connected to the wood material part (Figure 8 (C-1)). Cracks identified in the neck appear to have occurred in the molding clay layer, and based on the condition of the wood grain shapes, it is estimated that the wood material parts are connected from head to neck (Figure 8 (C-2)).
(2) Body

Considering the vertically oriented wooden joints identified on the body and the location of the identified clamp shape, it seems that the vertical wood material parts are connected horizontally to form the body. Several material parts with different wood grain shapes are connected on the left and right around the center of the body (Figure 9 (A-1)), and clamp shapes are consistently fixed according to the vertical shape (Figure 9 (A-2)). The arm parts next to each side of the body deviate from the vertical structure. In addition, oblique wood joints are observed (Figure 9 (A-3)), which appear to be irregular compared to the body part, and a number of nails have been used (Figure 9 (A-4, B, C)) Most of the thick and vivid connections from the body and shoulders to the abdominal area are identified along the joints. Moreover, while it is not clear because of the low transmittance of the lower part, it appears that the wood grain shapes in the joints of the wood material part of the body are connected to the lower body. Therefore, it seems that the
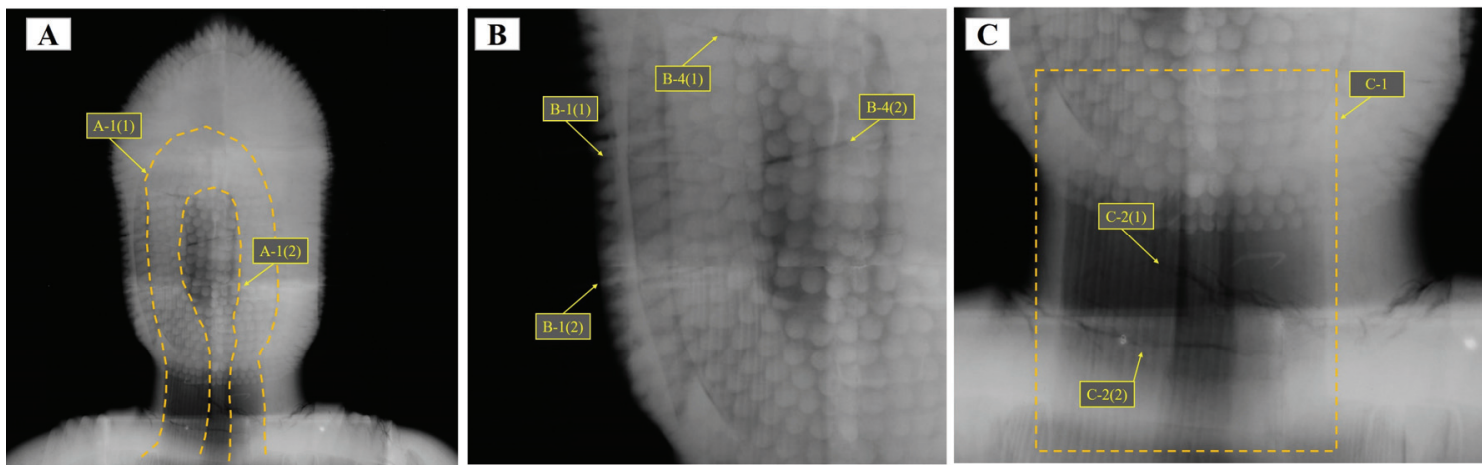

Figure 8. Radiography results of the head (Amitabha Buddha).
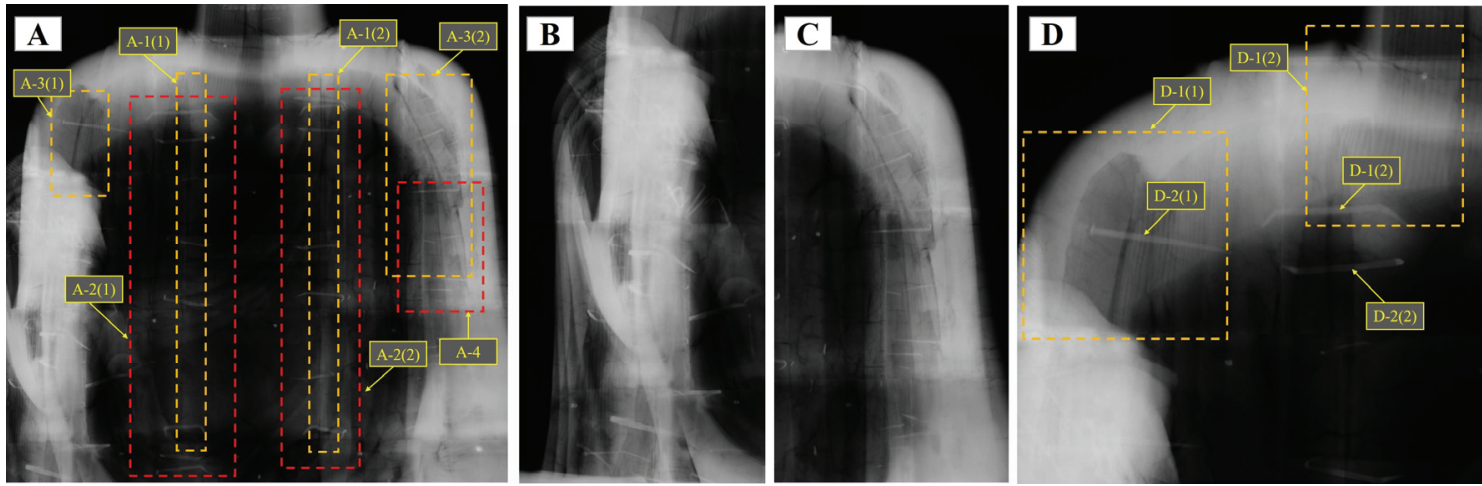

Figure 9. Radiography results of the body (Amitabha Buddha). 
vertically oriented wood material part was connected to the body and both arms (Figure 9 (D-1, D-2)), and the inside was created for the Bokjang-gong. The Bokjang-gong of the body appears to have been connected from the head and neck, and no relics were identified in the radiographic image. Overall, the wood grain shapes of the wood material part and the cracks in the molding clay layer appear together; thus, the construction of the body also seems to consist of wood material whose surface was lightly finished with soil.

\section{(3) Lower body}

The lower body is difficult to identify clearly owing to its low transmittance. Wood material parts with different wood grain shapes, such as horizontal sections and radial sections, were observed in various parts of the lower body (Figure 10 (A-1)), and some joints grafted with a base plate and lower body were identified (Figure 10 (B-1)). In addition, there are numerous traces of iron nails and clamps in the lower body area (Figure 10 (A-2, B-2)), which are thought to have been used to connect the base plate to the lower body or to reinforce the structure of the lower body. Although it is difficult to identify the lower part of the body owing to its significantly lower transmittance compared to that of the other Buddha statues, the inside of the lower body is empty for Bokjang-gong purposes (Figure 10 (A-3)), and there are traces of some wood material parts connecting the body to the lower body; therefore, the back material of the Buddha seems to be connected to the lower body (Figure 10 (A-4))

\subsubsection{Medicine Buddha}

(1) Head

Based on the radiological transmittance, the head shape was constructed with wood material, and the inside was emptied to prepare a Bokjang-gong (Figure 11 (A-1)). The ears were connected using a straight nail, but two iron nails were used to fix the left and right ears (Figure 11 (A-2)). Clamps appear in several parts of the head, but it is not certain whether they were made in the production process or used for repair purposes (Figure 11 (B-3)). In addition, one clamp was observed at the center of the neck (Figure 11 (C-1)), and cracks were identified to have occurred in the
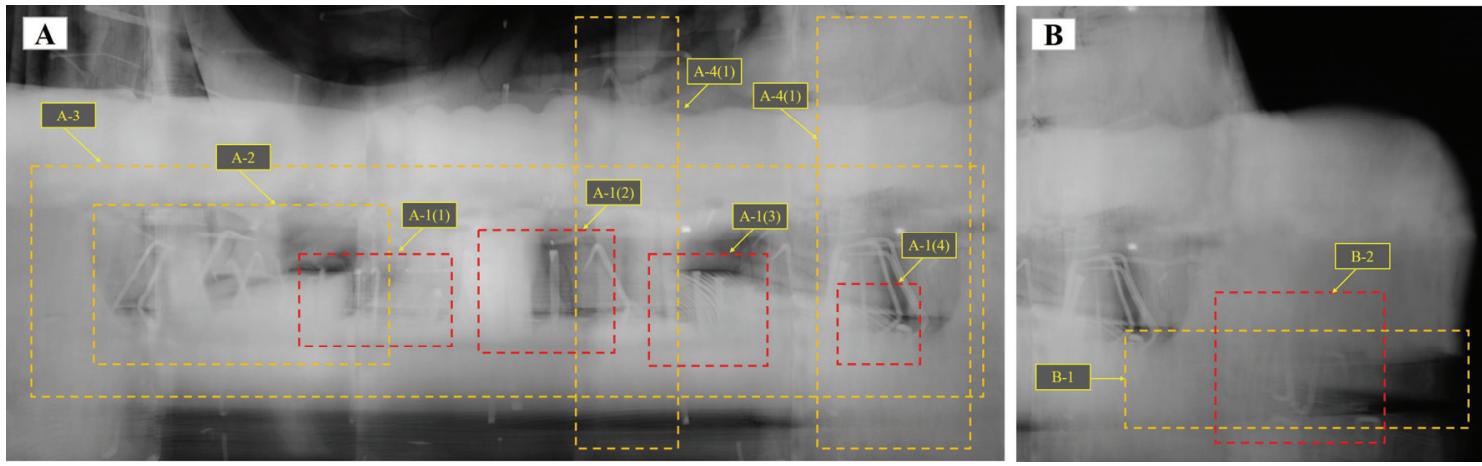

Figure 10. Radiography results of the lower body(Amitabha Buddha).
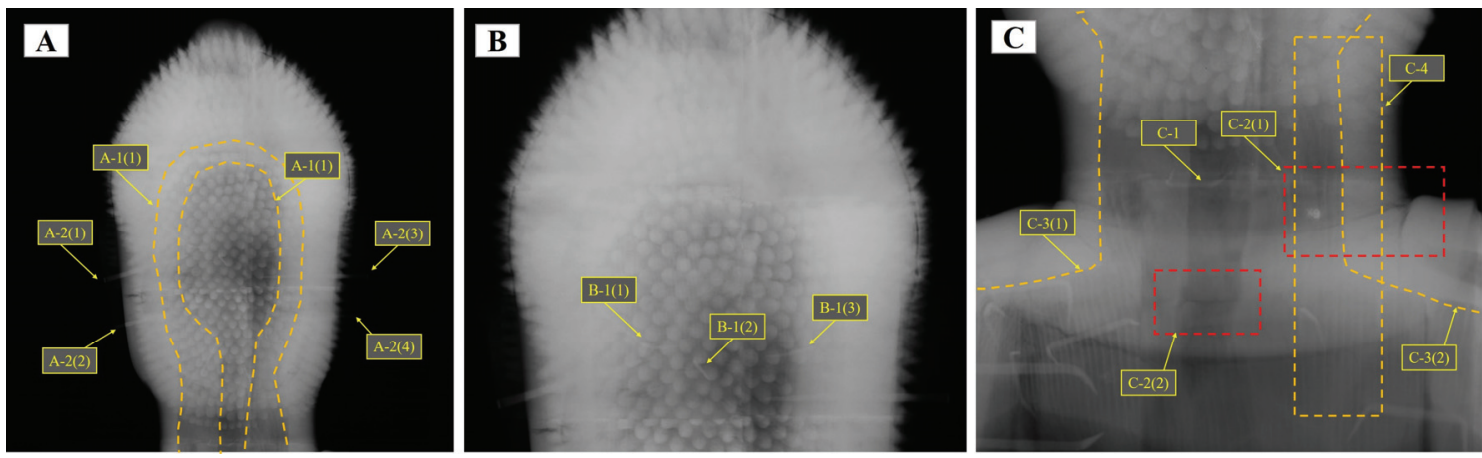

Figure 11. Radiography results of the head (Medicine Buddha). 
molding clay layer outside and below the neck (Figure 11 (C-2)). Considering that the Bokjang-gong of the head is connected to the neck (Figure $11(\mathrm{C}-3)$ ), and that the wood grain shape identified in the head is also connected to the neck, some of the wood material in the occipital region is assumed to be connected to the body (Figure 11 (C-4)).

\section{(2) Body}

The body, which comprises several material parts with different wood grain shapes, is divided vertically, and this divide appears to be the connecting area of the grafted part in the production process that connects some of the wood material parts (Figure 12 (A-1)). Therefore, it is believed that the body was formed by connecting the vertical material parts, and that the inside is empty and used for a Bokjang-gong. The joints of the body's wood material and wood grain shapes are connected from the neck to the lower body, which indicates that the head and Bokjang-gong are also connected. Considering the cracks in the molding clay layer and the wood grain shapes inside the body and throughout the shoulders and arms, it is thought that the body was constructed with wood materials and finished with a thin molding clay layer on top of the wood (Figure $12(\mathrm{~B}, \mathrm{C})$ ).

(3) Lower body

The lower body is difficult to identify clearly owing to its low transmittance, but the shape of the inner Bokjang-gong is approximately observed (Figure 13 (A-1)) compared to the Bonjon and Uhyeopsi, and a number of iron nails and clamps were used to connect the base plate to the lower body (Figure 13 (A-2)). Several wood grain shapes are also observed, such as horizontal and radial sections (Figure 13 (B-1)). Although it is not clearly identified because of the low transmittance of the upper part of the lower body, considering some of the identified connections of the material parts and the wood grain shapes of the body, it is thought that the wood material part used to form the back of the Buddha is connected from the body to the lower body (Figure $13(\mathrm{~B}-2))$.
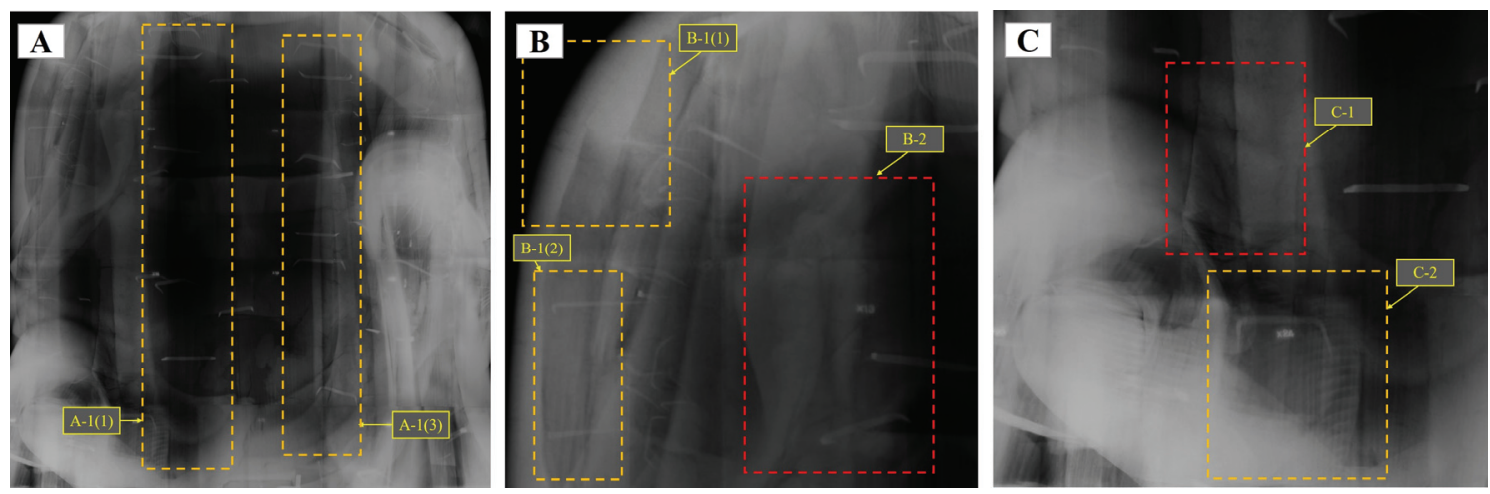

Figure 12. Radiography results of the body (Medicine Buddha).
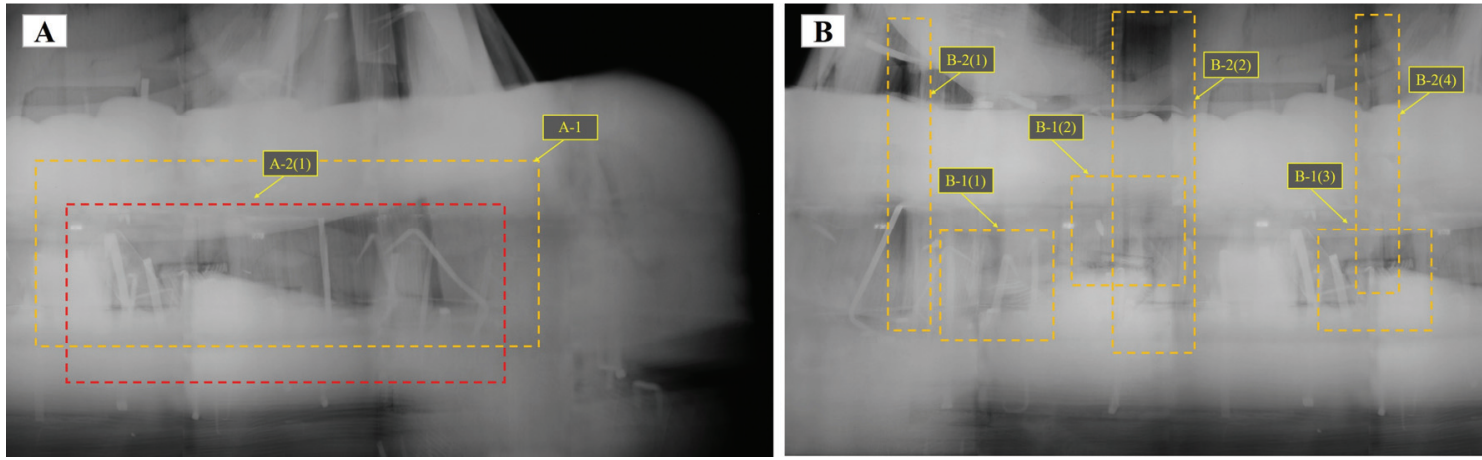

Figure 13. Radiography results of the lower body (Medicine Buddha). 


\section{CONCLUSION AND DISCUSSION}

The results of this investigation and analysis of the material characteristics and production methods of the Clay Seated Vairocana Buddha Triad of Seonunsa Temple are as follows.

The gold leaf layers of the Clay Seated Vairocana Buddha Triad of Seonunsa Temple are largely divided into the fabric layer, ground layer, presumed lacquer layer $\left(1^{\text {st }}\right)$, gold leaf layer $\left(1^{\text {st }}\right)$, presumed lacquer layer $\left(2^{\text {nd }}\right)$, gold leaf layer $\left(2^{\text {nd }}\right)$, repair layer (filling material), presumed lacquer layer $\left(3^{\text {rd }}\right)$, gold leaf layer $\left(3^{\text {rd }}\right)$, presumed lacquer layer $\left(4^{\text {th }}\right)$, and gold leaf layer $\left(4^{\text {th }}\right)$. The surface of the Buddha statue is gold foil, and the gold leaf layer consists of four layers. The gold leaf layer first placed on the molding clay was produced in the order of lacquer-fabrics-lacquer-gold foil. Subsequently, it was confirmed that the work was performed three times in the same way. In addition, during the process of forming the third gold leaf layer after the second gold leaf work, it was confirmed that a calcium-based substance was used to fill the upper side of the second layer of the gold leaf layer.

Based on the chemical composition analysis, a filling layer between the gold leaf layers of samples GL-1, GL-3, and GL-5 was identified as a material containing calcium (Ca) as the main component; therefore, it is possible that calcium carbonate $\left(\mathrm{CaCO}_{3}\right)$ containing calcium was used as the main material. However, in Sample GL-2, minerals such as magnesium $(\mathrm{Mg})$, calcium $(\mathrm{Ca})$, aluminum $(\mathrm{Al})$, and silicon (Si) derived from soil as well as lead $(\mathrm{Pb})$ were identified as the main components. Compared with the other samples, it is possible that gold mending work on the left side waist of the Vairocana Buddha was performed without complete removal of the existing materials. As calcium $(\mathrm{Ca})$ and sulfur (S) were identified as major components in the treatment material layer and filling layer on the back side of the Vairocana Buddha where treatment material was found (Sample GL-4), it is believed that material based on calcium sulfate $\left(\mathrm{CaSO}_{4}\right)$ was used in the treatment process and the formation of the foundation of the gold leaf layer.

Similar to the left knee part of the Bhaisaijyaguru Buddha (Sample GL-1), substances such as copper $(\mathrm{Cu})$ and chlorine (Cl) found in the upper gold leaf part of the first gold leaf layer are believed to be related to removing existing substances upon re-working during gold mending, and detailed follow-up research is required in this area.

Based on the radiographic results, the basic form of the Buddha statue was composed of wood materials, and the surfaces of the wood materials were finished by molding a clay layer to form the Buddha statue, with a similar process for all three Buddha statues. The body of the Buddha statue was grafted horizontally with vertically oriented wood materials and fixed using clamps, and the materials of the front and back plates were connected to the shoulder materials to form a cylindrical inner Bokjang-gong. In addition, the front part of the body is a grafted structure that reaches the lower part of the abdomen, and the abdominal material is thought to be connected to the base plate. Thus, the body and lower body appear to be connected to a single Bokjang-gong. It is difficult to identify the grafted shape in the head of the Buddha statue, but because the wood grain shape of the material is connected to the body, it is believed that the backside material is connected to the occipital. In all three statues of Buddha, the hand signs and ears were made separately, and the ears were connected with iron nails.

In the case of wooden surfaces, most of the Buddha's forms, including the face and body but excluding the hand sign and head-yukgyae, are believed to have been finished with earthen dough based on the observation of cracks in the molding clay layer throughout the radiographs. The radiography results showed no signs of past repair, and no factory nails used in modern times were identified.

According to the Series 1 study, analyses of the soil layer constituting the clay Buddha statues revealed that the soil layer was composed of a mixture of sand and loess, and bast fibers of the paper mulberry (Broussonetia kazinoki) were included to prevent scattering. In addition, in a tree species analysis, the wooden materials that comprise the clay Buddha statues were identified as hard pines (Pinus spp.) (Lee, et al., 2020). In domestic research studies, the fundamental skeleton of the small Buddha was formed with a wooden member, and the member was wrapped with a rope or wire, while the body was constructed with mud of excellent viscosity. The formed small clay layer is composed of two or more composite layers, and it is created by mixing fibers such as straw and seaweed to prevent the formation of cracks in the soil. In addition, in the case of molding clay, it was confirmed that the particle size distribution was configured differently according to the layer level (Han, 2005; Jeon, 
2009; Han et al., 2012; Lee et al., 2013). From these results, it can be seen that the Clay Seated Vairocana Buddha Triad of Seonunsa Temple has characteristics similar to previous results of research on the materials and manufacturing techniques of clay Buddha statues in Korea.

Therefore, it is believed that the Clay Seated Vairocana Buddha Triad of Seonunsa Temple was made using wood materials such as hard pines for basic form, after which the detailed form was created with molding clay by adding fiber to a sand and loess mixture; finally, the lacquer and gold leaf process was applied. This process is typical of the materials and techniques of Korean Clay Buddha statues, and it can be considered a traditional production style.

\section{REFERENCES}

Georim Culture Heritage and Gochang-gun, 2018, Records and investigation of conservation status reports on clay seated vairocana buddha triad of Seonunsa temple, Gochang. (in Korean)
Han, K.S., 2005, A study on the technological processes of four-guardian statutes at the Songkwang-sa, Suncheon. Journal of the Institute of Bibliography, 30, 97-114. (in Korean with English abstract)

Han, D.R., Lee, C.H. and Jo, Y.H., 2012, Interpretation of making techniques and material characteristics for molding clay of four guardian statues in Wanju Songkwangsa temple, Korea. Journal of Conservation Science, 28(4), 353-366. (in Korean with English abstract)

Jeon, K.M., 2009, On the production and the preservation of clay-statues from the Northern Ho-Nam region during the latter-Chosun era. The Art History Journal, 32, 179-209. (in Korean with English abstract)

Lee, H.S., Lee, H.H. and Han, G.S., 2020, Study on the characteristics of materials and production techniques of clay seated vairocana buddha triad of Seonunsa temple, Gochang. Journal of Conservation Science, 36(6), 562-577. (in Korean with English abstract)

Lee, J.E., Han, N.R. and Lee, C.H., 2013, Interpretation of making techniques and nondestructive diagnosis for the clay statues in Donggwanwangmyo Shrine, Seoul. Journal of Conservation Science, 29(1), 35-45. (in Korean with English abstract) 